\title{
Comparison of CFBP, FFBP, and RBF Networks in the Field of Crack Detection
}

\author{
Dhirendranath Thatoi, ${ }^{1}$ Punyaslok Guru, ${ }^{1}$ Prabir Kumar Jena, ${ }^{2}$ \\ Sasanka Choudhury, ${ }^{1}$ and Harish Chandra Das ${ }^{1}$ \\ ${ }^{1}$ Department of Mechanical Engineering, Institute of Technical Education and Research, SOA University, Bhubaneswar, \\ Odisha 751030, India \\ ${ }^{2}$ VSSUT, Burla, Odisha 768018, India
}

Correspondence should be addressed to Dhirendranath Thatoi; dnthatoi@gmail.com

Received 31 July 2013; Revised 26 October 2013; Accepted 22 November 2013; Published 4 February 2014

Academic Editor: Chia-Feng Juang

Copyright (C) 2014 Dhirendranath Thatoi et al. This is an open access article distributed under the Creative Commons Attribution License, which permits unrestricted use, distribution, and reproduction in any medium, provided the original work is properly cited.

\begin{abstract}
The issue of crack detection and its diagnosis has gained a wide spread of industrial interest. The crack/damage affects the industrial economic growth. So early crack detection is an important aspect in the point of view of any industrial growth. In this paper a design tool ANSYS is used to monitor various changes in vibrational characteristics of thin transverse cracks on a cantilever beam for detecting the crack position and depth and was compared using artificial intelligence techniques. The usage of neural networks is the key point of development in this paper. The three neural networks used are cascade forward back propagation (CFBP) network, feed forward back propagation (FFBP) network, and radial basis function (RBF) network. In the first phase of this paper theoretical analysis has been made and then the finite element analysis has been carried out using commercial software, ANSYS. In the second phase of this paper the neural networks are trained using the values obtained from a simulated model of the actual cantilever beam using ANSYS. At the last phase a comparative study has been made between the data obtained from neural network technique and finite element analysis.
\end{abstract}

\section{Introduction}

The presence of cracks in a mechanical member has catastrophic effects on its functionality and the failure in detecting the said cracks may result in failure of the mechanical member. Hence, studies related to crack detection has been a major field of interest among researchers and scholars. Crack detection using vibrational analysis is considered the most prolific and efficient technique in crack detection but the integration of vibrational analysis with artificial intelligence and soft computing techniques has provided new dimensions to crack detection and analysis.

There have been many papers suggesting different methods for detecting cracks in a simple cantilever beam by using vibrational analysis. The inverse measurement of crack parameters from vibrational analysis is the basis on which the crack analysis is done in this paper and the relevant literature in this regard is described as follows. Lifshitz and Rotem [1] pioneered the proposed damage detection via vibration measurements-inverse measurement of crack parameters from vibrational parameters. They look at the change in the dynamic moduli, which can be related to the frequency shift, as indicating damage in particle-filled elastomers. The dynamic moduli, which are the slopes of the extensional and rotational stress-strain curves under dynamic loading, are computed for the test articles from a curve-fit of the measured stress-strain relationships, at various levels of filling. By considering the change of modal frequencies as the key factor of damage, various researchers have used the inverse method for examining the changes of modal frequencies [2-13].

Many times, it is quite difficult to determine the crack parameters by presenting a physical model of the cantilever beam along with the crack. In order to examine and analyze the various parameters and simulate a simple crack on a cantilever beam efforts have been taken with the help of designing software. Apart from using a simulation software, researchers have used different means of analyzing the entire system. Sahoo et al. [14] have used ultrasonic 
signals to monitor the various vibrational changes and anomalies.

After the successful monitoring of these changes and anomalies a conclusion was made about the various crack parameters. In general if a person tries to reach such a conclusion by following a theoretical process it would take him a longer period of time as well as decrease the effectiveness and efficiency of the obtained result. Hence, various methods apart from the conventional technique are utilized to obtain a good and approximately exact result. Suresh et al. [15] presented a method by considering the flexural vibration in a cantilever beam with a transverse crack. They computed modal frequency parameters analytically for various crack locations and depths. After obtaining these values the parameters so obtained were used to train the neural network to identify the damage location and size. Saridakis et al. [16] proposed fuzzy logic, genetic algorithm (GA) and neural network for considering the dynamic behavior of a shaft with two transverse cracks characterized by position, depth, and relative angle. Little and Shaw [17] solved exactly a linearised version of the model. They explicitly show that the capacity of the memory is related to the number of synapses and not the number of neurons. A method was proposed by Loutridis et al. [18] "forced vibration behavior and crack detection of cracked beams using instantaneous frequency" to detect the crack in beam depending on instantaneous frequency (IF). The study monitored the dynamic behavior for the beam with breathing crack. They carried out the research under harmonic excitation with experimental and theoretical results. The observed data of the simulation and experimental test were analyzed using MATLAB. A relation between the depth of crack and the main difference of instantaneous frequency was established. The instantaneous frequency was found to be a good indicator for the size of crack.

Thatoi et al. [19] have reviewed the various methodologies used for crack detection and fault diagnosis. Doebling et al. [20] have reviewed different techniques of detection, location, and characterization of structural damage and faults. The analysis included changes in modal frequency, changes in mode shapes, and changes in flexibility coefficients.

Qian et al. [21] used a finite element model to predict the behavior of a beam with an edge crack by taking an element stiffness matrix, which is derived from an integration of stress intensity factor. Kim and Stubbs [22] located the position and estimated the size of a crack in beam type structures by taking the changes in natural frequencies, which is formulated by relating fractional changes in modal energy due to the presence of crack. Ihn and Chang [23] have proposed a method for detecting and monitoring hidden fatigue crack growth. They have used diagnostic signals, generated from nearby piezoelectric actuators built into the structure to detect the crack growth. A complete built-in diagnostic system for the tests was developed, including a sensor network, hardware, and the diagnostic software. Lele and Maiti [24] have considered the effect of shear deformation and rotational inertia through the Timoshenko beam theory for detection and measurement of crack extension of short beams. Quek et al. [25] have inspected the sensitivity of wavelet technique in the detection of cracks in beam-like structure. In this aspect they

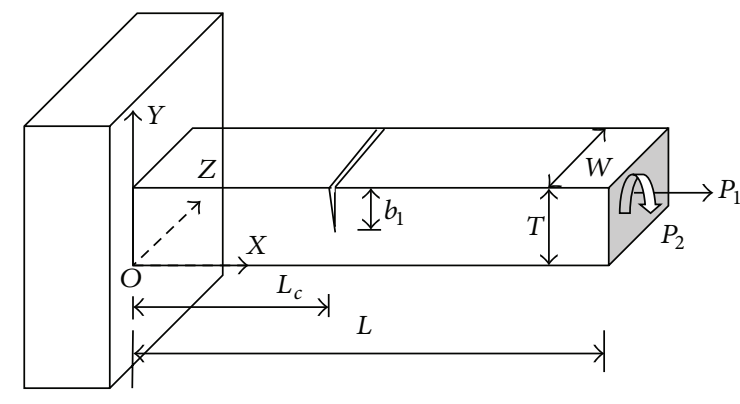

Figure 1: Beam model.

have compared the results of two wavelets such as: Haar and Gabor wavelets. Zagrai and Giurgiutiu [26] have described the utilization of electromechanical impedance method for crack detection in thin plates. This method allows the direct identification of structural dynamics by obtaining its electromechanical impedance.

Crack detection in the beam-like structures having single as well as multicracks was modeled using artificial neural network (ANN) and the various characteristics were studied [27-29].

In the present study a methodical approach to analyze and detect the crack parameters, that is, the crack location and relative crack depth from a set of frequency values obtained from a simulated model of the cantilever beam containing a thin transverse crack using ANSYS. Using the data, cascade forward back propagation (CFBP), feed forward back propagation (FFBP) and radial basis function (RBF) neural network models are developed and finally result thus obtained are compared.

\section{Mathematical Formulation}

2.1. Computation of Flexibility Matrix of a Damaged Beam Subjected to Complex Loading. A beam with cracks has smaller stiffness than a normal beam. This decreased local stiffness can be formulated as a matrix. The dimension of the matrix would depend on the degrees of freedom in the problem. Figure 1 shows a cantilever beam of width $W$ and height $T$, having a transverse surface crack of depth $b_{1}$. The beam experiences combined longitudinal and transverse motion due to the axial force $P_{1}$ and bending moment $P_{2}$. Here two degrees of freedom are considered, leading to a $2 \times 2$ local stiffness matrix.

The relationship between strain energy release rate $J(b)$ and stress intensity factors $\left(G_{I i}\right)$ at the crack section is given by Tada et al. [30] as

$$
J(b)=\frac{1}{E^{\prime}}\left(G_{I 1}+G_{I 2}\right)^{2}
$$

where $E^{\prime}=E /\left(1-v^{2}\right)$, for plane strain condition, and $E^{\prime}=E$, for plane stress, $G_{I 1}=$ stress intensity factor for opening mode $I$ due to load $P_{1}$, and $G_{I 2}=$ stress intensity factor for opening mode $I$ due to load $P_{2}$. 
From earlier studies (Tada et al. [30]), the values of stress intensity factors are

$$
\begin{aligned}
G_{I 1} & =\frac{P_{1}}{W T} \sqrt{\pi b}\left(F_{1}\left(\frac{b}{T}\right)\right), \\
G_{I 2} & =\frac{6 P_{2}}{W T^{2}} \sqrt{\pi b}\left(F_{2}\left(\frac{b}{T}\right)\right),
\end{aligned}
$$

where $0 \leq b \leq b_{1}$ and the experimentally determined functions $F_{1}$ and $F_{2}$ are expressed as follows:

$$
\begin{aligned}
F_{1}\left(\frac{b}{T}\right)= & \left(\frac{2 T}{\pi b} \tan \left(\frac{\pi b}{2 T}\right)\right)^{0.5} \\
\times & \left\{\left(0.752+2.02\left(\frac{b}{T}\right)\right.\right. \\
& \left.+0.37\left(1-\sin \left(\frac{\pi b}{2 T}\right)\right)^{3}\right) \\
& \left.\times\left(\cos \left(\frac{\pi b}{2 T}\right)\right)^{-1}\right\}, \\
F_{2}\left(\frac{b}{T}\right)=\left(\frac{2 T}{\pi b} \tan \left(\frac{\pi b}{2 T}\right)\right)^{0.5} & \times\left\{\frac{0.923+0.199(1-\sin (\pi b / 2 T))^{4}}{\cos (\pi b / 2 T)}\right\} .
\end{aligned}
$$

The strain energy release rate (also called strain energy density function) at the crack location is defined as

$$
J(b)=\frac{\partial U_{t}}{\partial(b \times W)},
$$

where $(b \times W)$ is the newly created surface area of the crack

$$
d U_{t}=J(b) d(b \times W)=W J(b) d b,
$$

since the width of the cross section of the beam is constant

$$
U_{t}=W \int_{0}^{b_{1}} J(b) d b .
$$

So the strain energy release $\left(U_{t}\right)$ due to the crack of depth $b_{1}$ is calculated.

Then from Castigliano's theorem, the additional displacement along the force $P_{i}$ is given as

$$
S_{i}=\frac{\partial U_{t}}{\partial P_{i}} .
$$

Using (1) and (6),

$$
\begin{gathered}
S_{i}=\frac{\partial}{\partial P_{i}}\left[W \int_{0}^{b_{1}} J(b) d b\right]=W \frac{\partial}{\partial P_{i}}\left[\int_{0}^{b_{1}} J(b) d b\right], \\
C_{i j}=\frac{\partial S_{i}}{\partial P_{j}}=\frac{\partial}{\partial P_{j}}\left[W \frac{\partial}{\partial P_{i}}\left\{\int_{0}^{b_{1}} J(b) d b\right\}\right] \\
=W \frac{\partial^{2}}{\partial P_{i} \partial P_{j}} \int_{0}^{b_{1}} J(b) d b .
\end{gathered}
$$

The flexibility influence coefficient $C_{i j}$ as per definition will be as follows.

By substituting (1) in (9),

$$
C_{i j}=\frac{W}{E^{\prime}} \frac{\partial^{2}}{\partial P_{i} \partial P_{j}} \int_{0}^{b_{1}}\left(G_{l 1}+G_{l 2}\right)^{2} d b .
$$

Putting $\delta=(b / T), d \delta=d b / T$, we get $d b=T d \delta$ and when $b=0, \delta=0 ; b=b_{1}, \delta=b_{1} / T=\delta_{1}$.

From the above condition (10) converts to

$$
C_{i j}=\frac{W T}{E^{\prime}} \frac{\partial^{2}}{\partial P_{i} \partial P_{j}} \int_{0}^{\delta_{1}}\left(G_{l 1}+G_{l 2}\right)^{2} d \delta .
$$

Equation (11) will give different expressions of flexibility influence coefficient $C_{i j}$.

$C_{i j}=$ flexibility influence coefficient in $i$ direction $(X-$ direction or $Y$-direction) due to the load in $j$ direction $\left(P_{1}\right.$ or $P_{2}$ ).

The expressions for $C_{11}, C_{12}\left(=C_{21}\right)$ and $C_{22}$ are obtained as follows:

$$
\begin{gathered}
C_{11}=\frac{W T}{E^{\prime}} \int_{0}^{\delta_{1}} \frac{\pi b}{W^{2} T^{2}} 2 F_{1}^{2}(\delta) d \delta \\
=\frac{2 \pi}{W E^{\prime}} \int_{0}^{\delta_{1}} \delta F_{1}^{2}(\delta) d \delta, \\
C_{12}=C_{21}=\frac{12 \pi}{E^{\prime} T W} \int_{0}^{\delta_{1}} \delta F_{1}(\delta) F_{2}(\delta) d \delta, \\
C_{22}=\frac{72 \pi}{E^{\prime} W T^{2}} \int_{0}^{\delta_{1}} \delta F_{2}^{2}(\delta) d \delta .
\end{gathered}
$$

The local stiffness matrix can be obtained by taking the inversion of compliance matrix. That is,

$$
K=\left[\begin{array}{ll}
K_{11} & K_{12} \\
K_{21} & K_{22}
\end{array}\right]=\left[\begin{array}{ll}
C_{11} & C_{12} \\
C_{21} & C_{22}
\end{array}\right]^{-1} .
$$

Converting the influence coefficient into dimensionless form,

$$
\begin{gathered}
\bar{C}_{11}=C_{11} \frac{W E^{\prime}}{2 \pi} ; \quad \bar{C}_{12}=C_{12} \frac{E^{\prime} T W}{12 \pi}=\bar{C}_{21} ; \\
\bar{C}_{22}=C_{22} \frac{E^{\prime} W T^{2}}{72 \pi} .
\end{gathered}
$$

\subsection{Governing Equations for Vibration Mode of the Cracked} Beam. The cantilever beam as mentioned in Section 2.1 is considered here for free vibration analysis. A cantilever beam of length " $L$ " width " $W$ " and depth " $T$ ", with a crack of depth " $b_{1}$ " at a distance " $L_{c}$ " from the fixed end is considered as shown in Figure 1 . Taking $S_{1}(x, t)$ and $S_{2}(x, t)$ as the amplitudes of longitudinal vibration for the sections before and after the crack position and $V_{1}(x, t), V_{2}(x, t)$ are the amplitudes of bending vibration for the same sections as shown in Figure 2. 


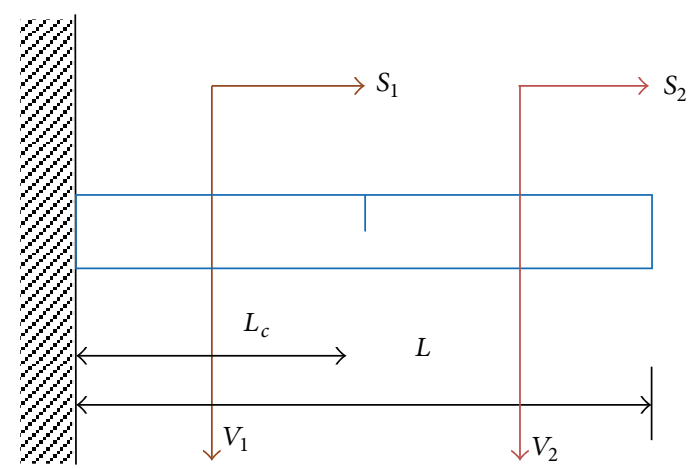

FIgURE 2: Beam model with deflection.

The free vibration of an Euler-Bernoulli beam of a constant rectangular cross section is given by the following differential equations as:

$\partial^{2} S / \partial t^{2}=(E / \rho) \partial^{2} S / \partial x^{2}$, for longitudinal vibration and

$E I\left(\partial^{4} V / \partial x^{4}\right)-\rho \omega^{2} V=0$, for lateral vibration of beam.

The normal functions for the cracked beam in nondimensional form for both the longitudinal and bending vibrations in steady state can be defined as

$$
\begin{array}{r}
\bar{S}_{1}(\bar{x})=B_{1} \cos \left(\bar{H}_{s} \bar{x}\right)+B_{2} \sin \left(\bar{H}_{s} \bar{x}\right), \\
\bar{S}_{2}(\bar{x})=B_{3} \cos \left(\bar{H}_{s} \bar{x}\right)+B_{4} \sin \left(\bar{H}_{s} \bar{x}\right) \\
\bar{V}_{1}(\bar{x})=B_{5} \cosh \left(\bar{H}_{v} \bar{x}\right)+B_{6} \sinh \left(\bar{H}_{v} \bar{x}\right) \\
+B_{7} \cos \left(\bar{H}_{v} \bar{x}\right)+B_{8} \sin \left(\bar{H}_{v} \bar{x}\right), \\
\bar{V}_{2}(\bar{x})=B_{9} \cosh \left(\bar{H}_{v} \bar{x}\right)+B_{10} \sinh \left(\bar{H}_{v} \bar{x}\right) \\
+B_{11} \cos \left(\bar{H}_{v} \bar{x}\right)+B_{12} \sin \left(\bar{H}_{v} \bar{x}\right),
\end{array}
$$

where $\bar{x}=x / L, \bar{S}=S / L, \bar{V}=V / L, \alpha=L_{c} / L$,

$$
\begin{gathered}
\bar{H}_{s}=\frac{\omega L}{D_{s}}, \quad D_{s}=\left(\frac{E}{\rho}\right)^{1 / 2}, \quad \bar{H}_{V}=\left(\frac{\omega L^{2}}{D_{v}}\right)^{1 / 2}, \\
D_{v}=\left(\frac{E I}{\mu}\right)^{1 / 2}, \quad \mu=A \rho,
\end{gathered}
$$

$B_{i},(i=1,12)$ constants are to be determined, from boundary conditions. The boundary conditions of the cantilever beam in consideration are

$$
\begin{array}{lll}
\bar{S}_{1}(0)=0 ; & \bar{V}_{1}(0)=0 ; & \bar{V}_{1}^{\prime}(0)=0 ; \\
\bar{S}_{2}^{\prime}(1)=0 ; & \bar{V}_{2}^{\prime \prime}(1)=0 ; & \bar{V}_{2}^{\prime \prime \prime}(1)=0 .
\end{array}
$$

At the cracked section,

$$
\begin{array}{cc}
\bar{S}_{1}(\alpha)=\bar{S}_{2}(\alpha) ; & \bar{V}_{1}(\alpha)=\bar{V}_{2}(\alpha) ; \\
\bar{V}_{1}^{\prime \prime}(\alpha)=\bar{V}_{2}^{\prime \prime}(\alpha) ; & \bar{V}_{1}^{\prime \prime \prime}(\alpha)=\bar{V}_{2}^{\prime \prime \prime}(\alpha) .
\end{array}
$$

Also at the cracked section,

$$
\begin{aligned}
A E \frac{d S_{1}\left(L_{c}\right)}{d x}= & K_{11}\left(S_{2}\left(L_{c}\right)-S_{1}\left(L_{c}\right)\right) \\
& +K_{12}\left(\frac{d V_{2}\left(L_{c}\right)}{d x}-\frac{d V_{1}\left(L_{c}\right)}{d x}\right) .
\end{aligned}
$$

Multiplying both sides of the above equation by $A E / L K_{11} K_{12}$,

$$
N_{1} N_{2} \bar{S}_{1}^{\prime}(\alpha)=N_{2}\left(\bar{S}_{2}(\alpha)-\bar{S}_{1}(\alpha)\right)+N_{1}\left(\bar{V}_{2}^{\prime}(\alpha)-\bar{V}_{1}^{\prime}(\alpha)\right) .
$$

Similarly,

$$
\begin{aligned}
E I \frac{d^{2} V_{1}\left(L_{c}\right)}{d x^{2}}= & K_{21}\left(S_{2}\left(L_{c}\right)-S_{1}\left(L_{c}\right)\right) \\
& +K_{22}\left(\frac{d V_{2}\left(L_{c}\right)}{d x}-\frac{d V_{1}\left(L_{c}\right)}{d x}\right) .
\end{aligned}
$$

Multiplying both sides of the above equation by $E I / L^{2} K_{22} K_{21}$,

$$
\begin{aligned}
N_{3} N_{4} \bar{V}_{1}^{\prime \prime}(\alpha)= & N_{3}\left(\bar{S}_{2}(\alpha)-\bar{S}_{1}(\alpha)\right) \\
& +N_{4}\left(\bar{V}_{2}^{\prime}(\alpha)-\bar{V}_{1}^{\prime}(\alpha)\right),
\end{aligned}
$$

where $N_{1}=A E / L K_{11}, N_{2}=A E / K_{12}, N_{3}=E I / L K_{22}, N_{4}=$ $E I / L^{2} K_{21}$.

The normal functions (15a), (15b), (15c), and (15d) along with the boundary conditions as mentioned above yield the characteristic equation of the system as

$$
|Q|=0
$$

where $Q$ is a $12 \times 12$ matrix as given below whose determinant is a function of natural circular frequency $(\omega)$, the relative location of the crack $(\alpha)$ and the local stiffness matrix $(K)$, which in turn is a function of the relative crack depth $\delta_{1}=$ $\left(b_{1} / T\right)$ : 

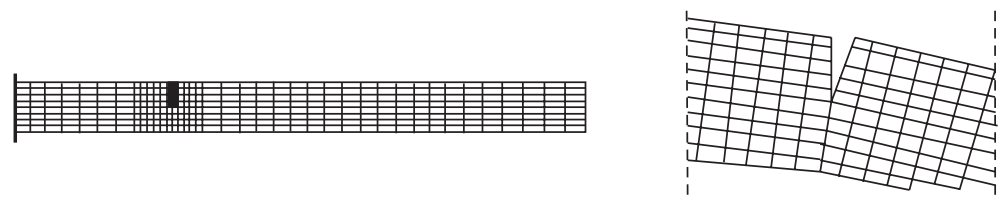

FIGURE 3: Finite element mesh and mesh zoom of the crack.

$$
Q=\left[\begin{array}{cccccccccccc}
1 & 0 & 1 & 0 & 0 & 0 & 0 & 0 & 0 & 0 & 0 & 0 \\
0 & 1 & 0 & 1 & 0 & 0 & 0 & 0 & 0 & 0 & 0 & 0 \\
0 & 0 & 0 & 0 & G_{3} & G_{4} & -G_{7} & -G_{8} & 0 & 0 & 0 & 0 \\
0 & 0 & 0 & 0 & G_{4} & G_{3} & G_{8} & -G_{7} & 0 & 0 & 0 & 0 \\
G_{1} & G_{2} & -G_{5} & -G_{6} & -G_{1} & -G_{2} & G_{5} & G_{6} & 0 & 0 & 0 & 0 \\
G_{2} & G_{1} & G_{6} & -G_{5} & -G_{2} & -G_{1} & -G_{6} & G_{5} & 0 & 0 & 0 & 0 \\
G_{1} & G_{2} & G_{5} & G_{6} & -G_{1} & -G_{2} & -G_{5} & -G_{6} & 0 & 0 & 0 & 0 \\
S_{1} & S_{2} & S_{3} & S_{4} & -G_{2} & -G_{1} & G_{6} & -G_{5} & S_{5} & S_{6} & S_{7} & S_{8} \\
0 & 0 & 0 & 0 & 0 & 0 & 0 & 0 & 1 & 0 & 0 & 0 \\
0 & 0 & 0 & 0 & 0 & 0 & 0 & 0 & 0 & 0 & -T_{8} & T_{7} \\
0 & 0 & 0 & 0 & 0 & 0 & 0 & 0 & -T_{6} & T_{5} & T_{6} & -T_{5} \\
S_{9} & S_{10} & S_{11} & S_{12} & S_{13} & S_{14} & S_{15} & S_{16} & S_{17} & S_{18} & -T_{5} & -T_{6}
\end{array}\right],
$$

where

$$
\begin{aligned}
& S_{1}=G_{2}+N_{3} \bar{H}_{v} G_{1}, \quad S_{2}=G_{1}+N_{3} \bar{H}_{v} G_{2}, \\
& S_{3}=-G_{6}-N_{3} \bar{H}_{v} G_{5}, \quad S_{4}=G_{5}-N_{3} \bar{H}_{v} G_{6} \text {, } \\
& S_{5}=\frac{N_{34}}{\bar{H}_{v}} T_{5}, \quad S_{6}=\frac{N_{34}}{\bar{H}_{v}} T_{6}, \quad S_{7}=\frac{-N_{34}}{\bar{H}_{v}} T_{5} \text {, } \\
& S_{8}=\frac{-N_{34}}{\bar{H}_{v}} T_{6}, \quad S_{9}=N_{12} \bar{H}_{v} G_{2}, \\
& S_{10}=N_{12} \bar{H}_{v} G_{1}, \quad S_{11}=-N_{12} \bar{H}_{v} G_{6}, \\
& S_{12}=N_{12} \bar{H}_{v} G_{5}, \quad S_{13}=-N_{12} \bar{H}_{v} G_{2}, \\
& S_{14}=-N_{12} \bar{H}_{v} G_{1}, \quad S_{15}=N_{12} \bar{H}_{v} G_{6}, \\
& S_{16}=-N_{12} \bar{H}_{v} G_{5}, \quad S_{17}=T_{5}-N_{1} \bar{H}_{s} T_{6} \text {, } \\
& S_{18}=T_{6}+N_{1} \bar{H}_{s} T_{5}, \\
& G_{1}=\operatorname{Cosh}\left(\bar{H}_{v} \alpha\right), \quad G_{2}=\operatorname{Sinh}\left(\bar{H}_{v} \alpha\right) \text {, } \\
& G_{3}=\operatorname{Cosh}\left(\bar{H}_{v}\right), \quad G_{4}=\operatorname{Sinh}\left(\bar{H}_{v}\right), \\
& G_{5}=\operatorname{Cos}\left(\bar{H}_{v} \alpha\right), \quad G_{6}=\operatorname{Sin}\left(\bar{H}_{v} \alpha\right), \\
& G_{7}=\operatorname{Cosh}\left(\bar{H}_{v}\right), \quad G_{8}=\operatorname{Sin}\left(\bar{H}_{v}\right), \\
& T_{5}=\operatorname{Cos}\left(\bar{H}_{s} \alpha\right) \text {, } \\
& T_{6}=\operatorname{Sin}\left(\bar{H}_{s} \alpha\right), \quad T_{7}=\operatorname{Cos}\left(\bar{H}_{s}\right), \quad T_{8}=\operatorname{Sin}\left(\bar{H}_{s}\right) \text {, } \\
& N_{12}=\frac{N_{1}}{N_{2}}, \quad N_{34}=\frac{N_{3}}{N_{4}} .
\end{aligned}
$$

\section{Finite Element Model Using ANSYS}

The vibrational analysis of a continuous beam by analytical procedures is quite appropriate and less complicated. However, with the introduction of crack in a beam the analysis of the beam for its vibrational characteristics becomes more complicated. Since the equation of motion of the continuous beam is a partial differential equation and we have with us various initial and boundary conditions we use the finite element method (FEM), which translates the complex partial differential equations into linear algebraic equations and hence the mode of solution becomes simpler.

In the present research the ANSYS is used as a tool to model and simulate a beam with a crack, to monitor the variation in its vibrational characteristics. The beam is modeled using design software such as solid work and it is imported to ANSYS for the analysis.

Now, after importing the model file, its geometry was modified and divided the entire structure into meshes (Figure 3) by using FEM and has been solved for the modes of frequencies. The meshing size should be increased so that it uniformly covers the entire structure. After the model is properly meshed and solved by using FEM, the various frequency values were obtained for a particular combination of crack location and depth.

The above procedure is elaborated as follows.

(1) Double click on workbench. Import geometry from solid works file saved in solid works as .igs file.

(2) Modify geometry, click on mesh, and increase the meshing size.

(3) Provide support and make one end fixed.

(4) Click on solve.

(5) Click on displacement. 


\section{The Inverse Tool: Artificial Neural Network}

In order to determine the crack parameters from the frequency data we take the help of artificial intelligence in the form of neural network. The structure of a neural net is very similar to the exact biological structure of a human brain cell. In order to be precise, neural network can be stated as a network model whose functionality is similar to that of the brain. In other words, a neural network is at first trained to recognize a predefined pattern or an already known relationship from certain prefound values. It works by taking certain number of inputs and computing the output after carefully adjusting the weights, which are attached with the input values to differentiate these input values on the basis of importance and priority in processing. These weight values are utilized to obtain the final output. For example, if we have two inputs $X_{1}$ and $X_{2}$, then a simple neural network can be designed and the net input can be found out as

$$
Y_{\text {in }}=x_{1} w_{1}+x_{2} w_{2},
$$

where $x_{1}$ and $x_{2}$ are the activations of the input neurons $X_{1}$ and $X_{2}$, that is, the output of the input signals. The output $y$ of the output neuron $Y$ can be obtained by applying activations over the net input, that is, the function of the net input:

$$
y=f\left(y_{\text {in }}\right)
$$

Output $=$ Function (net input calculated).

The function to be applied over the net input is called an activation function.

A neural network is classified on the basis of the model's synaptic interconnections, the learning rule adapted and the activation functions used in the neural net. Based on the synaptic interconnections we choose a multilayer perceptron model for our research purpose. Now, depending on the process of learning a neural network, it is classified as supervised learning network, unsupervised learning network, and reinforced learning network. Supervised learning process requires a set of already known values to train the network and hence find out the output. From the set of values obtained after monitoring the vibrational characteristics of the cracked beam and subjecting it to finite element modeling, the corresponding values are trained to the network. The tansigmoid hyperbolic function is chosen as the activation function. Finally the cascade forward back propagation (CFBP) network model, the feed forward back propagation (FFBP) network model, and the radial basis function $(\mathrm{RBF})$ network model are used and the results are analysed.

4.1. The CFBP Network. As stated earlier in the present study a CFBP network (Figure 4) is used. This network is very similar to the feed forward back propagation networks with the difference being that the input values calculated after every hidden layer are back-propagated to the input layer and the weights adjusted subsequently. The input values are directly connected to the final output and a comparison occurs between the values obtained from the hidden layers

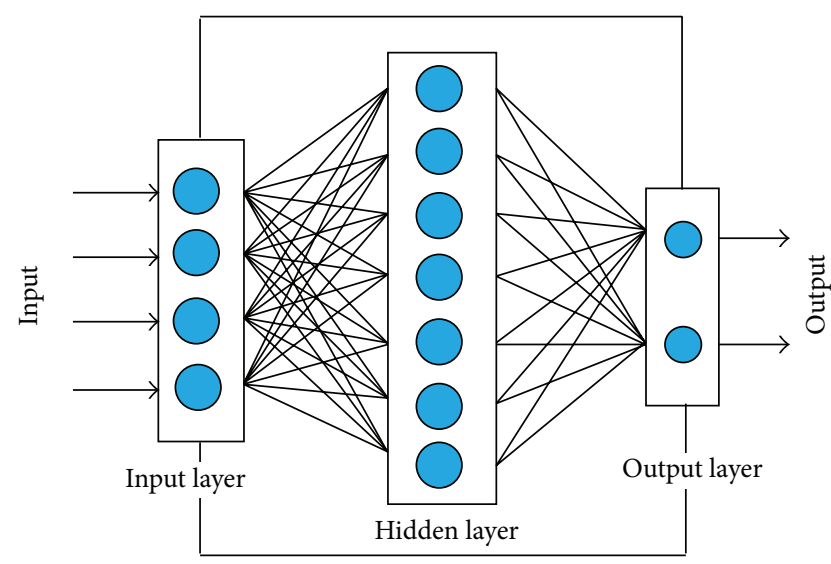

FIGURE 4: Structure of CFBP network.

and the values obtained from the input layers and weights are adjusted accordingly.

Sahoo et al. [14] and Gopikrishnan et al. [31] observed that the results obtained from CFBP networks are much more efficient than the FFBP networks. Badde et al. [32] suggested that CFBP networks show better and efficient results in most cases.

The algorithm followed in the present paper is given as follows.

(1) Initialize the predefined input matrix.

(2) Initialize the desired output or target matrix.

(3) Initialize the network by using the net = newcf (Input, Output, Hidden layers, Transfer Function, Training algorithm, Learning Function, Performance Function).

(4) Define the various training parameters such as number of epochs, number of validation checks, and maximum and minimum gradient.

(5) Test the new found weights and biases for accuracy.

(6) Using the weights and biases determine the unknown results.

The initial weight and bias values are taken as 0 (zero).

In Figure 4, the inputs are connected to the hidden layer as well as the output layer.

4.2. The FFBP Network. Another network that we are using for our comparative study in the detection of cracks in a cantilever beam is the feed forward back propagation (FFBP) network (Figure 5). This network differs from the CFBP network on the basis that each subsequent layer has a weight coming from the previous layer and no connection is made between the layers and the first layer. All layers have biases. The last layer is the network output.

In this study relevant information comparing the results of both networks as well as the result from a third network is presented. The algorithm used for CFBP network is also used in case of the FFBP network except for the network creation mode, which uses the keyword newff. 


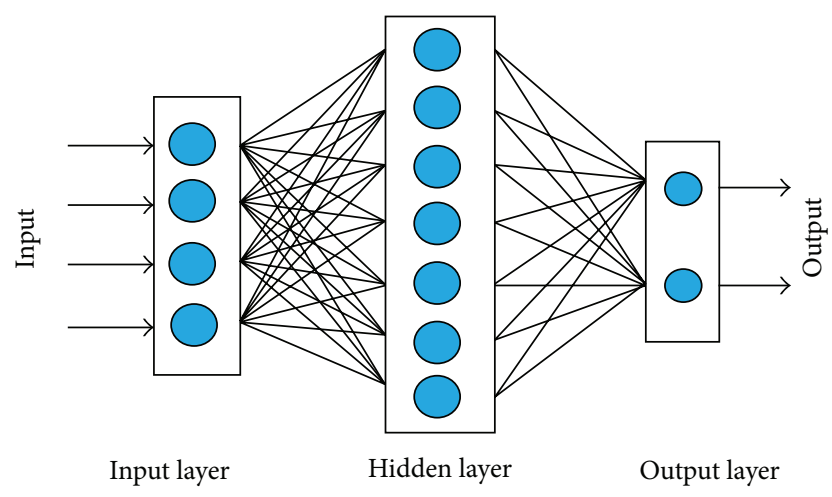

FIGURE 5: Structure of a FFBP network.

4.3. The RBF Network. The radial basis function (RBF) network (Figure 6) is basically used to find the least number of hidden layers or neurons in a single hidden layer, until a minimum error value is reached. The RBF networks can be used to approximate functions. For network creation the keyword newrb adds neurons to the hidden layer of a radial basis network until it meets the specified mean squared error goal.

\section{Results and Discussions}

As discussed earlier the motive of this paper is to detect the location of a single crack formed on a cantilever beam. A methodology involving ANN and ANSYS was followed to get the results and was discussed. To begin with, a transverse thin crack is formed on a cantilever beam. Finite element modeling is applied in the cracked beam using ANSYS to monitor the various frequencies in different modes of crack formation. Based on this sample data, a neural network has been trained to find out the crack depth and location of any arbitrary transverse crack on a cantilever beam.

Hence, there are two steps in present mode of solution:

(1) monitoring the vibrational changes using ANSYS;

(2) creating an ANN and training it to provide us with an approximate result.

A thin transverse crack is present on a cantilever beam of length $26 \mathrm{~cm}$ and with this crack a beam model is designed using ANSYS to obtain a set of natural frequencies for the first, second, and third modes at different crack locations with varying crack depths.

Cascade forward back propagation network, feed forward back propagation network, and radial basis function network were used to estimate the crack location and relative crack depth. A single hidden layer was used with 13 neurons. The TANSIG hyperbolic tangent sigmoid transfer function or activation function was used to calculate the final output of the neural net.

The TANSIG transfer function is given as

$$
\tan \operatorname{sig}(n)=\frac{2}{1+e^{-2 n}}-1 \text {. }
$$

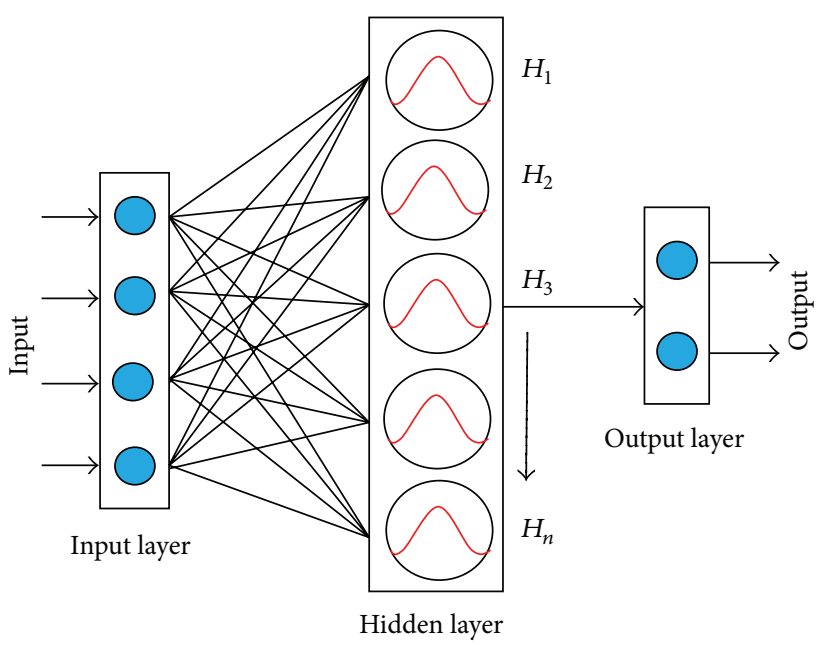

FIGURE 6: Structure of RBF neural network.

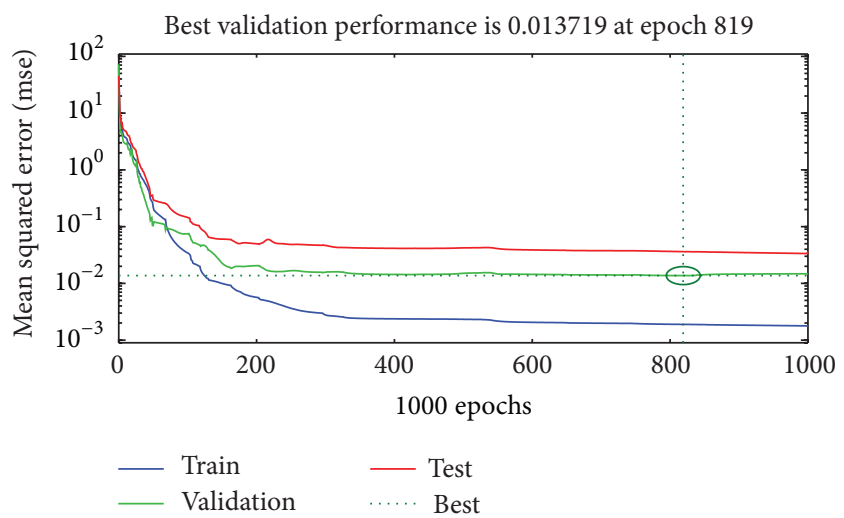

FiguRE 7: Performance graph of CFBP network.

The Levenberg-Marquardt (trainlm) training process was followed to train the neural network. Training stops when any of these conditions occurs.

(1) The maximum number of epochs (repetitions) is reached.

(2) The maximum amount of time has been exceeded.

(3) Performance has been minimized to the goal.

The division of training data was done using the random (Dividerand) method.

The number of iterations provided was 200. The gradient was set at a maximum value of 1 and minimum value of 0 . The performance or goal or maximum number of error checks was set to be 150 . There was no constraint on the amount of time for which the training program ran. Since the number of values employed for testing was large in number, hence, few values were taken to depict the efficiency of the ANN model. The tested data for a relative crack depth of 0.1 and varying locations was tabulated and a comparison with the actual data is shown in Table 1.

The network formed, generating a performance plot which is shown in Figure 7 by mentioning the relationship 


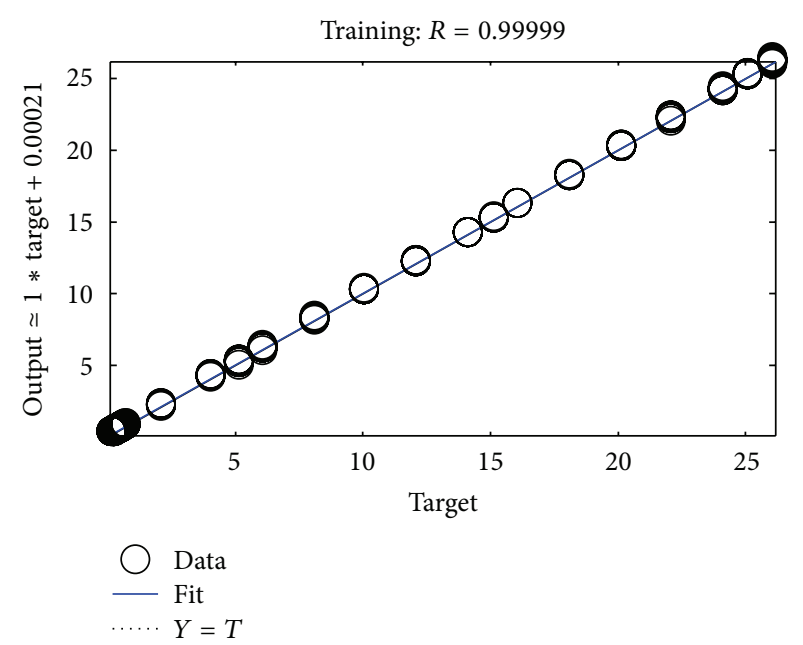

(a)

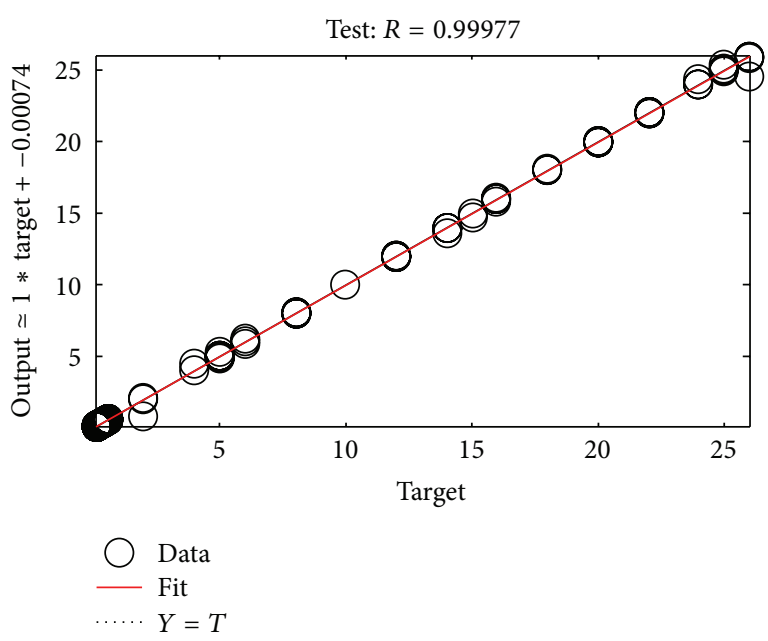

(c)

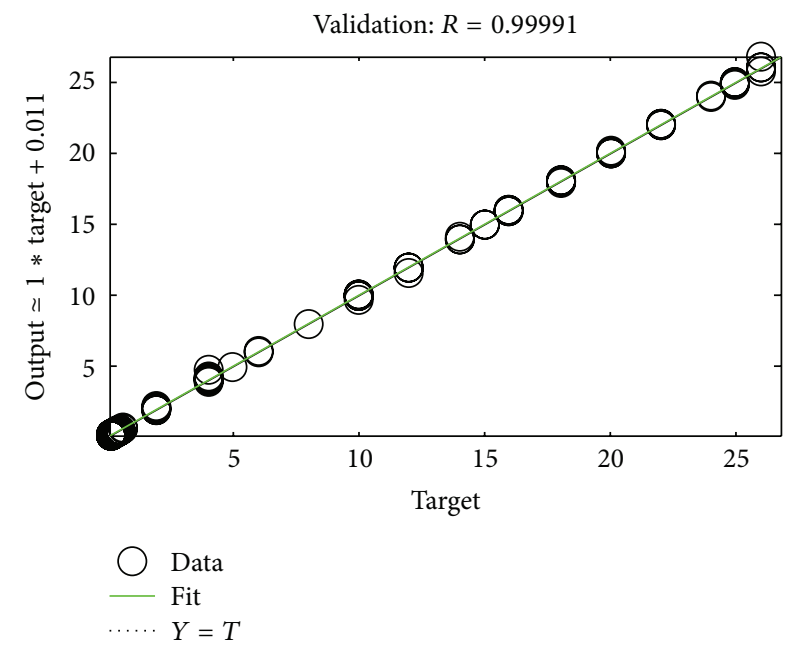

(b)

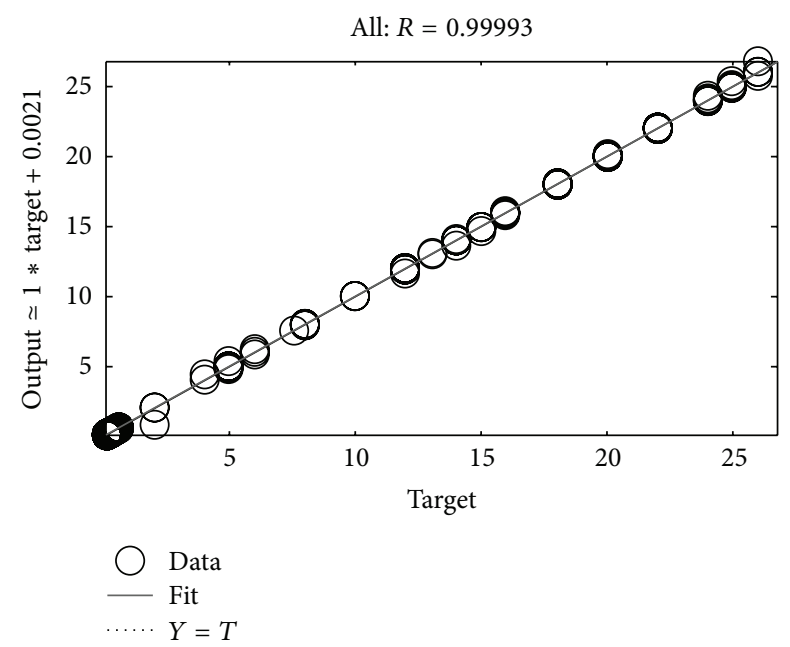

(d)

FIGURE 8: Regression plot of CFBP network.

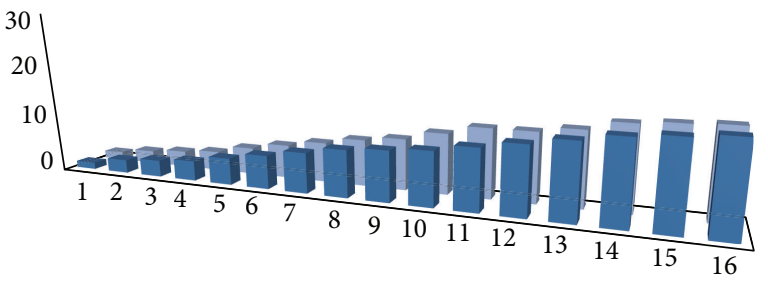

Location obtained from ANSYS

Location obtained from ANN

FIgURE 9: Comparison of result of location between ANSYS and CFBP network.

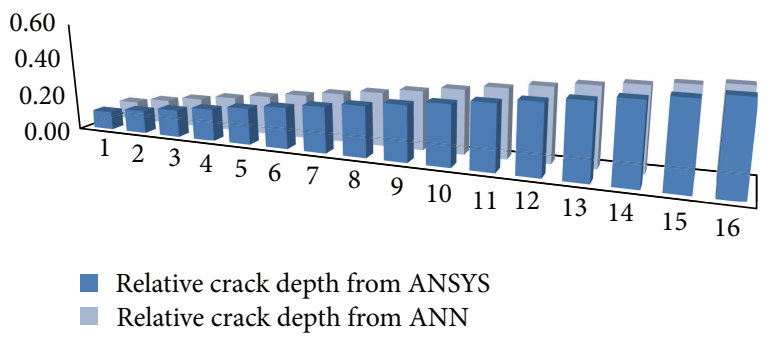

FIGURE 10: Comparison of result of relative crack depth between ANSYS and CFBP network.

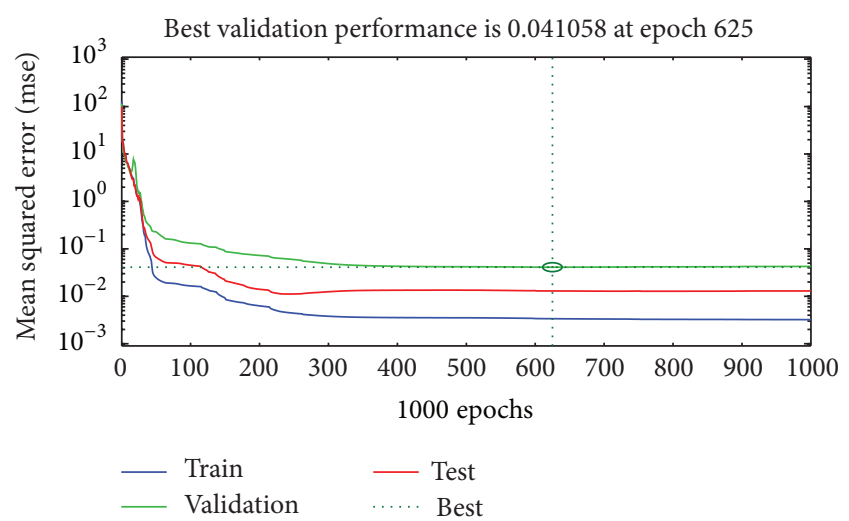

FiguRE 11: Performance graph of FFBP network.

between the trained, tested, and validated points against a threshold value.

A regression plot is also generated which is shown in Figure 8 for the individual results obtained. 

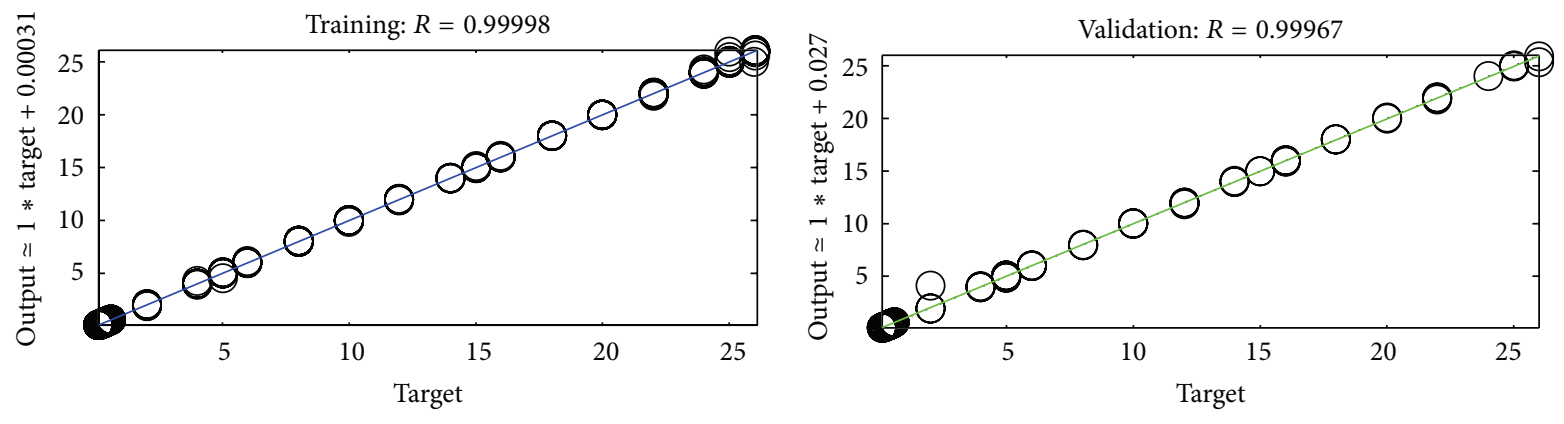

$$
\begin{array}{ll}
\cdots & Y=T \\
& \text { Fit } \\
& \text { Data }
\end{array}
$$

(a)

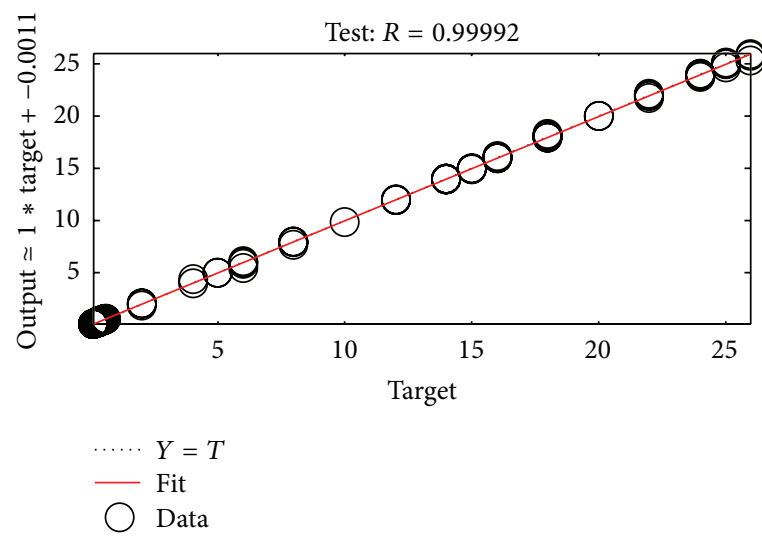

(c) $\begin{array}{ll}\cdots \cdots & Y=T \\ & \text { Fit } \\ & \text { Data }\end{array}$

(b)

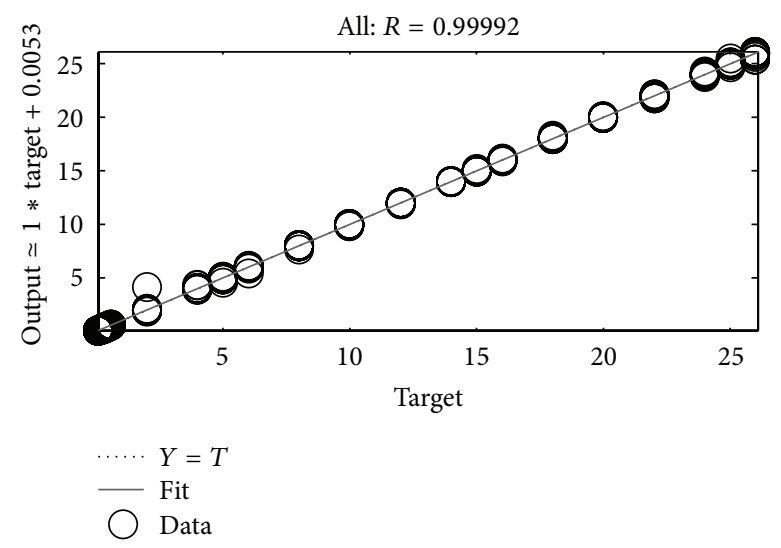

(d)

FIGURE 12: Regression plot of FFBP network.

On plotting the values obtained from ANSYS and ANN and comparing both, it was observed that minimum difference was obtained between both of the values thus validating our training process. The plots of crack location for the values represented in Table 1 are shown in Figure 9.

The plot of Figure 10 shows the comparison of results for varius crack depths obtained from ANSYS and CFBP network by fixing the crack location.

It was observed that after running the CFBP network for a particular number of iterations a certain value of error between the ANSYS generated values and the network generated values was obtained. It is essential to mention that the error obtained here is of the order of $10^{-2}$ and in general for any number of iterations run over any period of time and keeping the above mentioned parameters (except the number of epochs) constant, the error obtained is of the same order and varying upto $10^{-4}$ under a uniform testing, training, and validation situation.

After observing the results of CFBP network, the FFBP network is introduced for the comparative study. In this network 13 hidden neurons and a single hidden layer have been taken. The activation function, training function, the division of data function, number of iterations, gradient value and all the parameters are similar to those used for the CFBP network. After training the data to FFBP network with the similar process (by keeping relative crack depth constant and varying the location), the results are obtained and the comparison with the results of actual data is presented in Table 2.

Similar to CFBP network the performance plot and the regression plot of FFBP network obtained from the trained data are shown in Figures 11 and 12, respectively.

On plotting the values obtained from ANSYS and ANN and comparing both, it has been observed that minimum difference was obtained between both of the values, thus validating our training process. The plots of crack location for the values represented in Table 2 are shown in Figure 13.

Figure 14 shows the comparison of results for varius crack depths obtained from ANSYS and FFBP network by fixing the crack location.

In comparison with CFBP network it is observed that the FFBP network is showing the better results. For the above case the CFBP network gives the best validation performance in terms of root mean square error (RMSE) value of 0.018464 , whereas the FFBP network gives 0.041058 which shows that the mean squared error calculated in case of the CFBP network is lower than that of the FFBP network. 


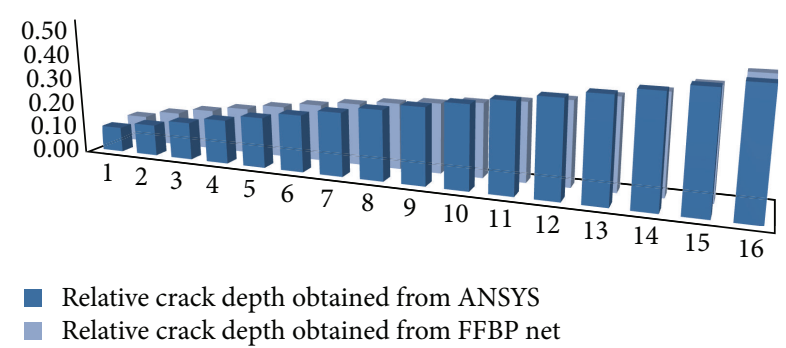

FIGURE 13: Comparison of result of relative crack depth between ANSYS and FFBP network.

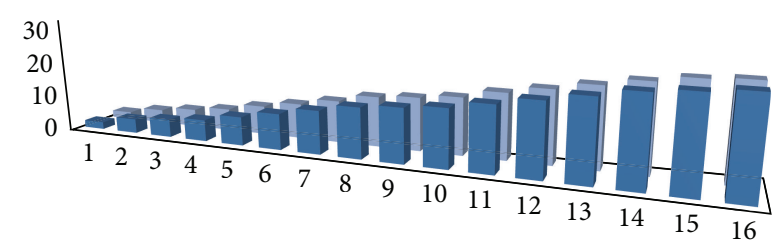

- Location obtained from ANSYS

- Location obtained from FFBP net

FIGURE 14: Comparison of result of crack location between ANSYS and FFBP network.

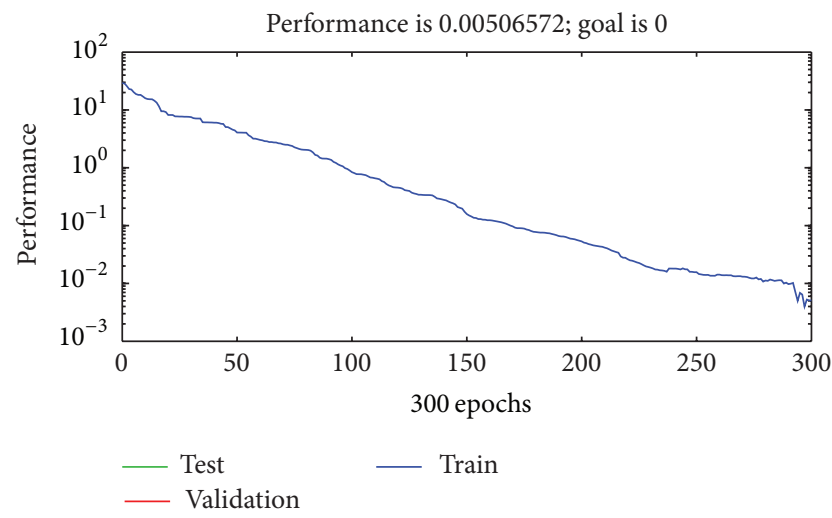

FiguRE 15: Performance graph of RBF network.

The RBF network is used then to complete the comparative study. The RBF network takes the input and output data used for training, which we get from ANSYS. The default value of the mean squared error goal set in the RBF network is 0.0 and the spread value is also taken as the default value, which is 1.0. The more the spread, the smoother the function approximation. Basically the newrb keyword creates a twolayered network. The results obtained and the comparisons with the results of actual data are shown in Table 3.

The RBF network generated a performance plot, which is different from the CFBP and FFBP networks on the grounds that in an RBF network a particular goal is set to be reached but the number of iterations is not fixed. For this particular case it was observed that the errors generated in all cases are of the order of $10^{-3}$ and the RBF network certainly yields a better

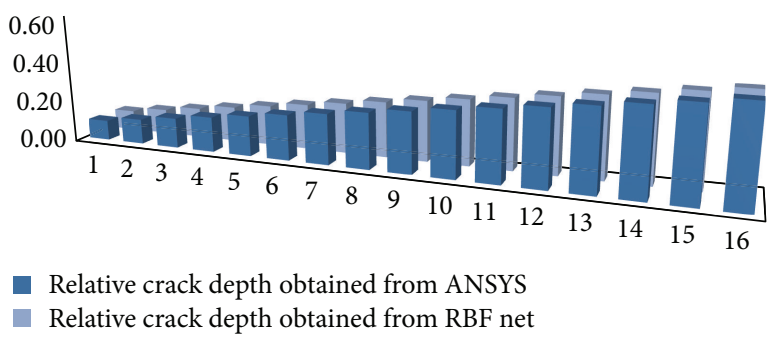

FIGURE 16: Comparison of result of relative crack depth between ANSYS and RBF network.

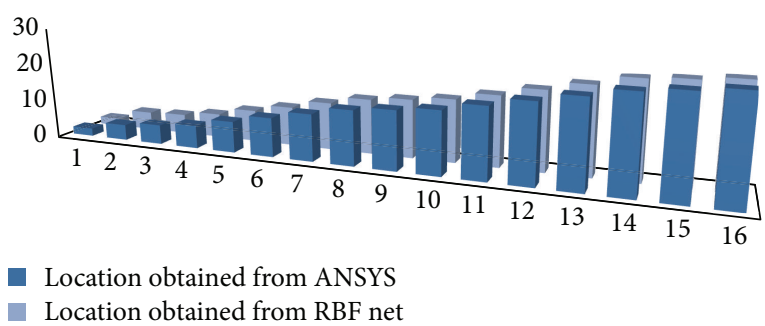

FIGURE 17: Comparison of result of crack location between ANSYS and RBF network.

result at more frequent intervals than the CFBP and the FFBP networks. The performance plot is shown in Figure 15.

In similarity to CFBP and FFBP network a comparison plot has been obtained from the various results of actual data and RBF network for relative crack depth and crack location and is shown in Figures 16 and 17, respectively.

After observing the results of various networks used (CFBP, FFBP, and RBF) a comparison of results has been made and is shown in Table 4. In the following table a comparative study has been made between the three neural network techniques in comparison with ANSYS and also the percentage of error has been presented. It was observed that for some cases RBF network result outperforms the results of the other two networks. But in general CFBP was found to be more efficient in terms of error and computational complexity.

Ultimately after observing the training process of all three networks and individually comparing the results of each of the networks, the three networks combined together with respect to the relative crack depth and crack location. We find that the result obtained from all three networks is very similar with marginal differences at certain particular points. By comparing the results of relative crack depth and crack location for the three networks, a comparison plot among three networks have been drawn and these are shown in Figure 18 and Figure 19. The point to note is that overall deductions suggest that RBF network gives the optimum result. The CFBP net is much more flexible on the grounds that we can alter its efficiency by varying the number and size of the hidden layers.

Table 5 shows the various properties of the material used for the above study. 
TABLE 1: Input data and results for CFBP network.

\begin{tabular}{lcccccc}
\hline \multicolumn{2}{c}{ Test points } & \multicolumn{3}{c}{ First three natural frequencies (Hz) } & \multicolumn{2}{c}{ CFBP } \\
rcd & Location & 1st mode & 2nd mode & 3rd mode & rcd & Location \\
\hline 0.100 & 2.000 & 48.209 & 302.187 & 846.297 & 846.630 & 0.103 \\
0.100 & 4.000 & 48.214 & 302.270 & 846.758 & 0.125 & 3.836 \\
0.100 & 5.000 & 48.216 & 302.305 & 846.845 & 0.129 & 0.126 \\
0.100 & 6.000 & 48.219 & 302.340 & 847.003 & 5.809 \\
0.100 & 8.000 & 48.221 & 302.400 & & 0.127 \\
\hline
\end{tabular}

TABLE 2: Input data and results for FFBP network.

\begin{tabular}{|c|c|c|c|c|c|c|}
\hline \multicolumn{2}{|c|}{ Test points } & \multicolumn{3}{|c|}{ First three natural frequencies $(\mathrm{Hz})$} & \multicolumn{2}{|c|}{ FFBP } \\
\hline $\mathrm{rcd}$ & Location & 1st mode & 2nd mode & 3rd mode & $\mathrm{rcd}$ & Location \\
\hline 0.100 & 2.000 & 48.209 & 302.187 & 846.297 & 0.106 & 2.030 \\
\hline 0.100 & 4.000 & 48.176 & 302.010 & 845.879 & 0.096 & 3.765 \\
\hline 0.100 & 5.000 & 48.134 & 301.797 & 845.399 & 0.098 & 4.952 \\
\hline 0.100 & 6.000 & 48.086 & 301.549 & 844.821 & 0.096 & 6.148 \\
\hline 0.100 & 8.000 & 48.031 & 301.261 & 844.155 & 0.095 & 8.093 \\
\hline
\end{tabular}

TABLE 3: Input data and results for RBF network.

\begin{tabular}{|c|c|c|c|c|c|c|}
\hline \multicolumn{2}{|c|}{ Test points } & \multicolumn{3}{|c|}{ First three natural frequencies $(\mathrm{Hz})$} & \multicolumn{2}{|c|}{$\mathrm{RBF}$} \\
\hline $\mathrm{rcd}$ & Location & 1st mode & 2nd mode & 3rd mode & $\mathrm{rcd}$ & Location \\
\hline 0.100 & 2.000 & 48.209 & 302.187 & 846.297 & 0.099 & 1.964 \\
\hline 0.100 & 4.000 & 48.176 & 302.010 & 845.879 & 0.102 & 4.678 \\
\hline 0.100 & 5.000 & 48.134 & 301.797 & 845.399 & 0.150 & 5.012 \\
\hline 0.100 & 6.000 & 48.086 & 301.549 & 844.821 & 0.098 & 6.176 \\
\hline 0.100 & 8.000 & 48.031 & 301.261 & 844.155 & 0.101 & 8.131 \\
\hline
\end{tabular}

TABLE 4: Comparison of results among CFBP, RBF, and FFBP network.

\begin{tabular}{lcccccccccc}
\hline \multicolumn{2}{c}{ Test points } & \multicolumn{2}{c}{ First three natural frequencies (Hz) } & \multicolumn{2}{c}{ CFBP } & \multicolumn{3}{c}{ FFBP } & \multicolumn{2}{c}{ RBF } \\
rcd & Location & 1st mode & 2nd mode & 3rd mode & rcd & Location & rcd & Location & rcd & Location \\
\hline 0.100 & 2.000 & 48.209 & 302.187 & 846.297 & 0.103 & 2.329 & 0.106 & 2.030 & 0.099 & 1.964 \\
0.100 & 4.000 & 48.176 & 302.010 & 845.879 & 0.125 & 3.836 & 0.096 & 3.765 & 0.102 & 4.678 \\
0.100 & 5.000 & 48.134 & 301.797 & 845.399 & 0.129 & 4.809 & 0.098 & 4.952 & 0.150 & 5.012 \\
0.100 & 6.000 & 48.086 & 301.549 & 844.821 & 0.126 & 5.809 & 0.096 & 6.148 & 0.098 & 6.176 \\
0.100 & 8.000 & 48.031 & 301.261 & 844.155 & 0.127 & 8.115 & 0.095 & 8.093 & 0.101 & 8.131 \\
0.100 & 10.000 & 48.226 & 302.448 & 847.068 & 0.150 & 10.095 & 0.089 & 9.802 & 0.099 & 9.982 \\
0.100 & 12.000 & 48.229 & 302.481 & 847.051 & 0.141 & 11.925 & 0.088 & 11.725 & 0.101 & 12.098 \\
0.100 & 14.000 & 48.234 & 302.503 & 846.976 & 0.094 & 13.908 & 0.082 & 13.918 & 0.100 & 13.978 \\
0.100 & 15.000 & 48.236 & 302.511 & 846.928 & 0.135 & 15.248 & 0.079 & 14.767 & 0.099 & 14.908 \\
\hline
\end{tabular}

TABLE 5: Material properties of aluminum-alloy, 2014- $T_{4}$.

\begin{tabular}{ccccc}
\hline $\begin{array}{c}\text { Young's } \\
\text { modulus } \\
E\end{array}$ & $\begin{array}{c}\text { Density } \\
\rho\end{array}$ & $\begin{array}{c}\text { Poisson's } \\
\text { ratio } \\
\mu\end{array}$ & $\begin{array}{c}\text { Length } \\
L\end{array}$ & $\begin{array}{c}\text { Diameter } \\
D\end{array}$ \\
\hline $72.4 \mathrm{GPa}$ & $2.8 \mathrm{gm} / \mathrm{cc}$ & 0.33 & $800 \mathrm{~mm}$ & $150 \mathrm{~mm}$ \\
\hline
\end{tabular}

\section{Conclusion}

The effects of transverse cracks on the vibrating uniform cracked cantilever beam have been presented in this paper. The main purpose of this research work has been to develop a proficient technique for diagnosis of crack in a vibrating structure in short span of time. The vibration analysis has been done using theoretical and also it has been carried out through using finite element method as per ANSYS. In this analysis natural frequency plays an important role in the identification of crack. Crack has been identified in terms of crack depth and crack location. The results obtained from ANSYS are used to develop artificial intelligence techniques using three neural networks (FFBP, RBF, and CFBP). The CFBP network shows a better result than the FFBP network; the CFBP network gives the best validation performance of 0.018464 , whereas the FFBP network gives 0.041058 . It was observed that for some cases RBF network result outperforms the results of the other two networks. But in general CFBP was found to be more efficient in terms of error and computational complexity. As it was observed that the 


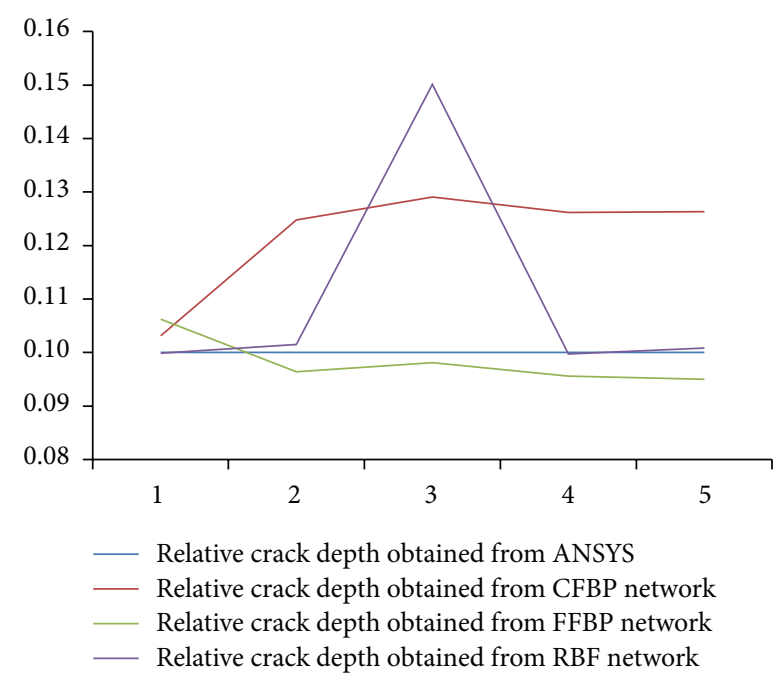

FIGURE 18: Overall comparison of result of relative crack depth among ANSYS, CFBP, FFBP, and RBF networks.

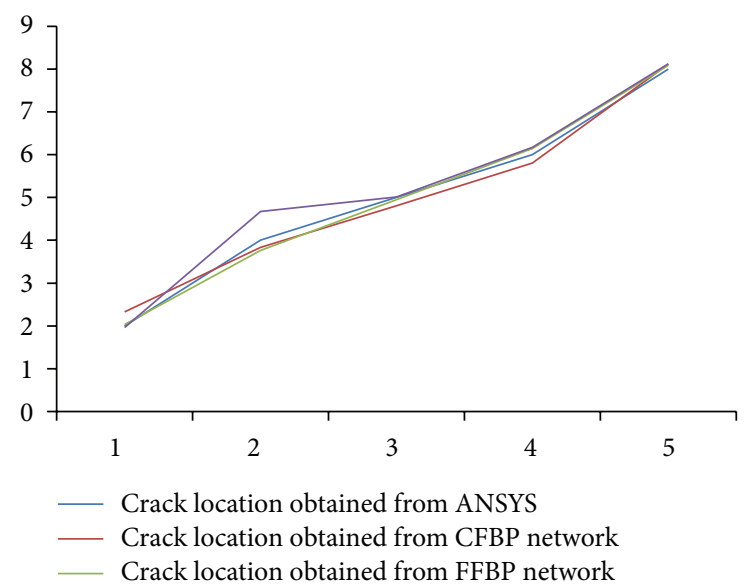

FIGURE 19: Overall comparison of result of crack location among ANSYS, CFBP, FFBP, and RBF networks.

predicted results of neural network technique are reasonably adequate and in agreement with the theoretical result, the developed models can be efficiently used for crack detection problems.

\section{Conflict of Interests}

The authors declare that they have no conflict of interests regarding the publication of this paper.

\section{References}

[1] J. M. Lifshitz and A. Rotem, "Determination of reinforcement unbonding of composites by a vibration technique," Journal of Composite Materials, vol. 3, no. 3, pp. 412-423, 1969.
[2] R. D. Adams, P. Cawley, C. J. Pye, and B. J. Stone, "A vibration technique for non-destructively assessing the integrity of structures," Journal of Mechanical Engineering Science, vol. 20, no. 2, pp. 93-100, 1978.

[3] W. Wang and A. Zhang, "Sensitivity analysis in fault vibration diagnosis of structures," in Proceedings of the 5th International Modal Analysis Conference, pp. 496-501, 1987.

[4] N. Stubbs, T. H. Broome, and R. Osegueda, "Nondestructive construction error detection in large space structures," AIAA journal, vol. 28, no. 1, pp. 146-152, 1990.

[5] G. Hearn and R. B. Testa, "Modal analysis for damage detection in structures," Journal of Structural Engineering, vol. 117, no. 10, pp. 3042-3063, 1991.

[6] M. H. Richardson and M. A. Mannan, "Remote detection and location of structural faults using modal parameters," in Proceedings of the 10th International Modal Analysis Conference, pp. 502-507, 1992.

[7] D. R. Sanders, Y. I. Kim, and N. Stubbs, "Nondestructive evaluation of damage in composite structures using modal parameters," Experimental Mechanics, vol. 32, no. 3, pp. 240-251, 1992.

[8] Y. Narkis, "Identification of crack location in vibrating simply supported beams," Journal of Sound and Vibration, vol. 172, no. 4, pp. 549-558, 1994.

[9] R. Brincker, P. H. Kirkegaard, P. Anderson, and M. E. Martinez, "Damage detection in an offshore structure," in Proceedings of the 13th International Modal Analysis Conference, pp. 661-667, 1995.

[10] L. BalisCrema, A. Castellani, and G. Coppotelli, "Generalization of non destructive damage evaluation using modal parameters," in Proceedings of the 13th International Modal Analysis Conference, pp. 428-431, 1995.

[11] P. S. Skjaerbaek, S. R. K. Nielsen, and A. S. Cakmak, "Assessment of damage in seismically excited RC-structures from a single measured response," in Proceedings of the 14th International Modal Analysis Conference, pp. 133-139, 1996.

[12] A. AL-Qaisia and U. Meneghetti, "Crack detection in plates by sensitivity analysis," in Proceedings of the 15th International Modal Analysis Conference (IMAC '97), pp. 1831-1837, Orlando, Fla, USA, February 1997.

[13] I. Villemure, C. E. Ventura, and R. G. Sexsmith, "Impact and ambient vibration testing to assess structural damage in reinforced concrete beams," in Proceedings of the 14th International Modal Analysis Conference, Dearborn, Michigan, 1996.

[14] A. K. Sahoo, Y. Zhang, and M. J. Zuo, "Estimating crack size and location in a steel plate using ultrasonic signals and CFBP neural networks," in Proceedings of the IEEE Canadian Conference on Electrical and Computer Engineering (CCECE '08), pp. 17511754, May 2008.

[15] S. Suresh, S. N. Omkar, R. Ganguli, and V. Mani, "Identification of crack location and depth in a cantilever beam using a modular neural network approach," Smart Materials and Structures, vol. 13, no. 4, pp. 907-915, 2004.

[16] K. M. Saridakis, A. C. Chasalevris, C. A. Papadopoulos, and A. J. Dentsoras, "Applying neural networks, genetic algorithms and fuzzy logic for the identification of cracks in shafts by using coupled response measurements," Computers and Structures, vol. 86, no. 11-12, pp. 1318-1338, 2008.

[17] W. A. Little and G. L. Shaw, "Analytic study of the memory storage capacity of a neural network," Mathematical Biosciences, vol. 39, no. 3-4, pp. 281-290, 1978. 
[18] S. Loutridis, E. Douka, and L. J. Hadjileontiadis, "Forced vibration behaviour and crack detection of cracked beams using instantaneous frequency," NDT and E International, vol. 38, no. 5, pp. 411-419, 2005.

[19] D. N. Thatoi, H. C. Das, and D. R. Parhi, "Review of techniques for fault diagnosis in damaged structure and engineering system," Advances in Mechanical Engineering, vol. 2012, Article ID 327569, 11 pages, 2012.

[20] S. W. Doebling, C. R. Farrar, M. B. Prime, and D. W. Shevitz, "Damage identification and health monitoring of structural and mechanical systems from changes in their vibration characteristics: a literature review," Tech. Rep. LA-13070-MS, Los Alamos National Laboratory, Los Alamos, NM, USA, 1996.

[21] G.-L. Qian, S.-N. Gu, and J.-S. Jiang, "The dynamic behaviour and crack detection of a beam with a crack," Journal of Sound and Vibration, vol. 138, no. 2, pp. 233-243, 1990.

[22] J.-T. Kim and N. Stubbs, "Crack detection in beam-type structures using frequency data," Journal of Sound and Vibration, vol. 259, no. 1, pp. 145-160, 2003.

[23] J.-B. Ihn and F.-K. Chang, "Detection and monitoring of hidden fatigue crack growth using a built-in piezoelectric sensor/actuator network: II. Validation using riveted joints and repair patches," Smart Materials and Structures, vol. 13, no. 3, pp. 621-630, 2004.

[24] S. P. Lele and S. K. Maiti, "Modelling of transverse vibration of short beams for crack detection and measurement of crack extension," Journal of Sound and Vibration, vol. 257, no. 3, pp. 559-583, 2002.

[25] S.-T. Quek, Q. Wang, L. Zhang, and K.-K. Ang, "Sensitivity analysis of crack detection in beams by wavelet technique," International Journal of Mechanical Sciences, vol. 43, no. 12, pp. 28992910, 2001.

[26] A. N. Zagrai and V. Giurgiutiu, "Electro-mechanical impedance method for crack detection in thin plates," Journal of Intelligent Material Systems and Structures, vol. 12, no. 10, pp. 709-718, 2001.

[27] P. R. Baviskar and V. B. Tungikar, "Multiple cracks assessment using natural frequency measurement and prediction of crack properties by artificial neural network," International Journal of Advanced Science and Technology, vol. 54, pp. 23-38, 2013.

[28] A. Das, S. Sivaprasad, M. Tarafder, S. K. Das, and S. Tarafder, "Estimation of damage in high strength steels," Applied Soft Computing, vol. 13, no. 2, pp. 1033-1041, 2013.

[29] D. N. Thatoi and P. K. Jena, "Inverse analysis of crack in fixedfixed structure by neural network with the aid of modal analysis," Advances in Artificial Neural Systems, vol. 2013, Article ID 150209, p. 8, 2013.

[30] H. Tada, P. C. Paris, and G. R. Irwin, The Stress Analysis of Cracks Hand Book, Del Research Corporation, Hellertown, Pennsylvanian, 1973.

[31] M. Gopikrishnan and T. Santhanam, "Effect of different neural networks on the accuracy in iris patterns recognition," International Journal of Reviews in Computing, vol. 7, pp. 22-28, 2011.

[32] D. S. Badde, A. K. Gupta, and V. K. Patki, "Cascade and feed forward back propagation artificial neural network models for prediction of compressive strength of ready mix concrete," IOSR Journal of Mechanical and Civil Engineering, vol. 3, pp. 1-6, 2013. 

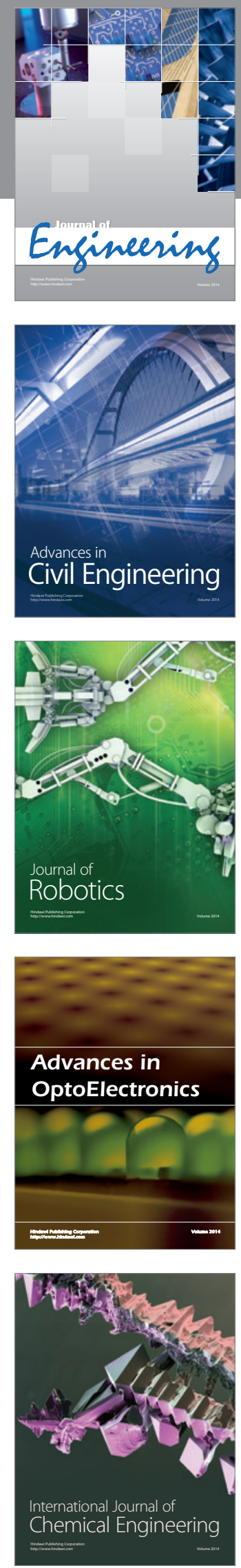

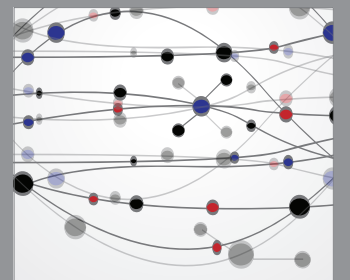

The Scientific World Journal
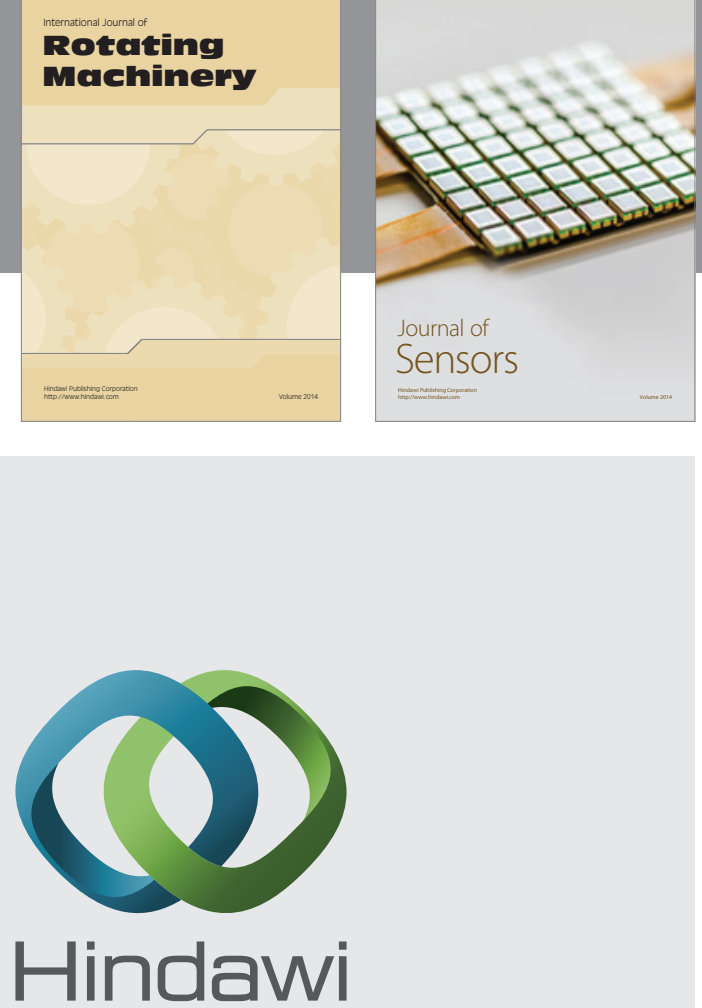

Submit your manuscripts at http://www.hindawi.com
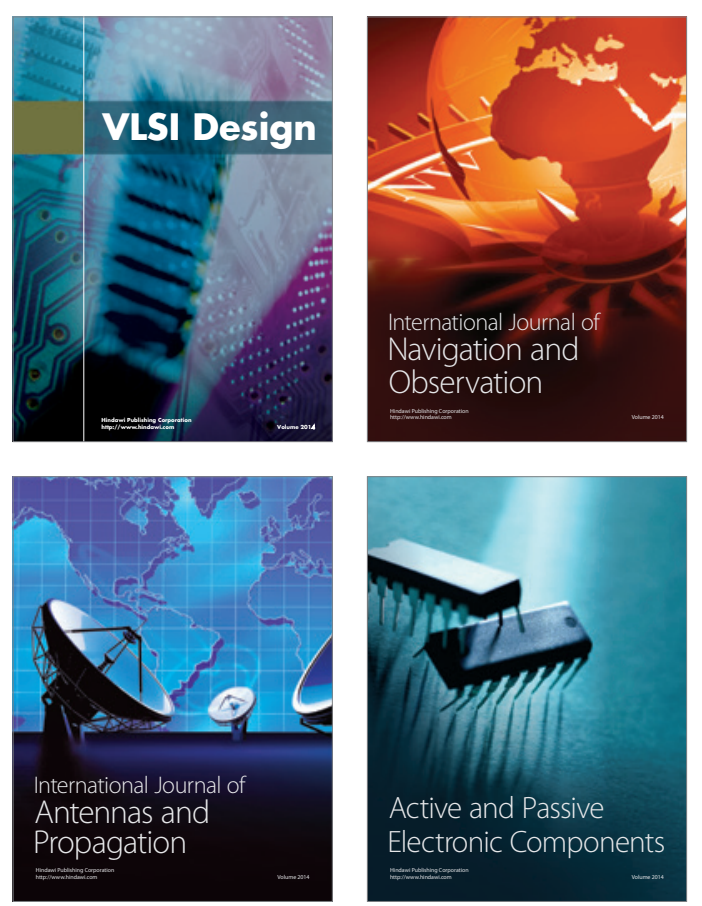
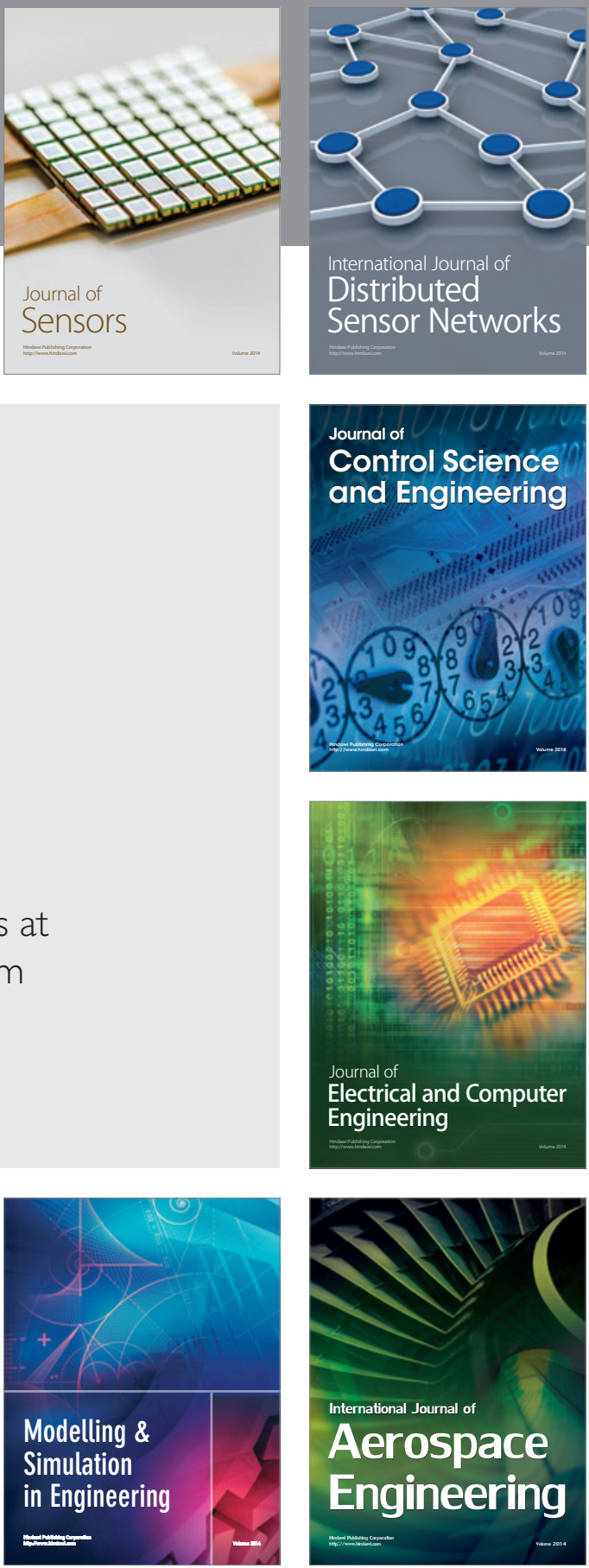

Journal of

Control Science

and Engineering
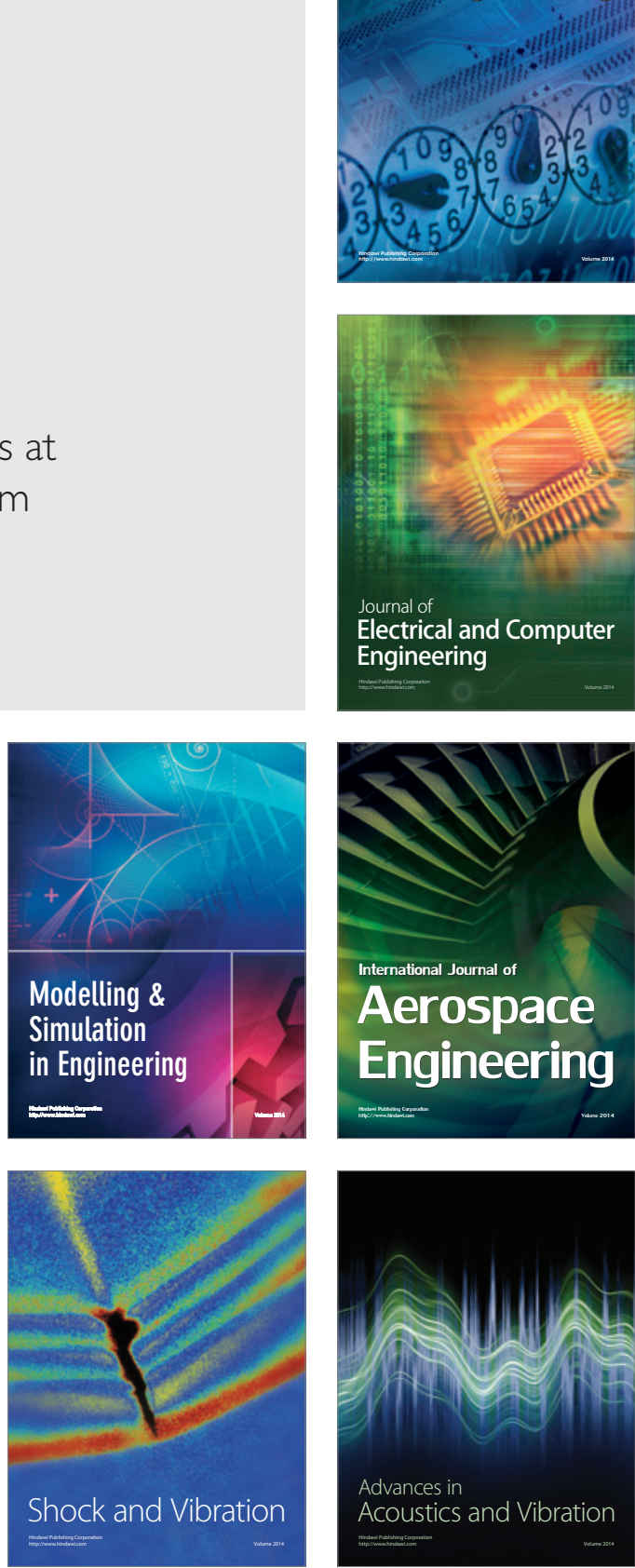